\title{
A Heuristic Framework of Spatial Ability: a Review and Synthesis of Spatial Factor Literature to Support its Translation into STEM Education
}

\author{
Jeffrey Buckley $^{1}$ (D) $\cdot$ Niall Seery ${ }^{1,2}$ (D) $\cdot$ Donal Canty $^{3}$ (D)
}

Published online: 2 March 2018

(C) The Author(s) 2018. This article is an open access publication

\begin{abstract}
An abundance of empirical evidence exists identifying a significant correlation between spatial ability and educational performance particularly in science, technology, engineering and mathematics (STEM). Despite this evidence, a causal explanation has yet to be identified. Pertinent research illustrates that spatial ability can be developed and that doing so has positive educational effects. However, contention exists within the relevant literature concerning the explicit definition for spatial ability. There is therefore a need to define spatial ability relative to empirical evidence which in this circumstance relates to its factor structure. Substantial empirical evidence supports the existence of unique spatial factors not represented in modern frameworks. Further understanding such factors can support the development of educational interventions to increase their efficacy and related effects in STEM education. It may also lead to the identification of why spatial ability has such a significant impact on STEM educational achievement as examining more factors in practice can help in deducing which are most important. In light of this, a synthesis of the spatial factors offered within existing frameworks with those suggested within contemporary studies is presented to guide further investigation and the translation of spatial ability research to further enhance learning in STEM education.
\end{abstract}

Keywords Spatial ability $\cdot$ Spatial factors $\cdot$ STEM education $\cdot$ Human intelligence

Jeffrey Buckley

jbuckley@kth.se

1 KTH Royal Institute of Technology, Stockholm, Sweden

2 Athlone Institute of Technology, Athlone, Ireland

3 University of Limerick, Limerick, Ireland 


\section{Introduction and Context}

Spatial abilities are one of the most studied factors of human cognitive functioning (Carroll 1993). Despite this, Lohman (1996) noted that they have long been relegated to a secondary status within human intelligence research. Among other reasons, Lohman (1996) attributes this second class status in part as being due to inconsistencies of spatial skills as predictors for educational success. Lohman (1996) also noted that other cognitive factors such as fluid and crystallised intelligences are better predictors of educational success and psychometric tests of spatial skills were in some instances potentially poor measures of spatial ability. Recently however, interest in spatial ability has seen a resurgence as it is becoming increasingly linked through correlational evidence with educational performance specifically in the areas of science, technology, engineering and mathematics (STEM) (Höffler 2010; Lubinski 2010; McGrew and Evans 2004; Wai et al. 2009). As a result, a substantial amount of contemporary research has focused on further uncovering the factor structure of spatial ability. This work has proved to be beneficial to the design of interventions which have resulted in increased STEM educational performance and retention (Sorby 2009; Sorby and Baartmans 2000; Sorby et al. 2013). However, research studies categorically illustrating a causal effect remain outstanding (Ramey and Uttal 2017; Stieff and Uttal 2015), and therefore it is not scientifically known how or why these interventions are achieving the results they are. Additionally, this is difficult to investigate as spatial ability is hard to observe in practice and its definition within the literature is contentious. In light of this, the agenda of this paper is to review the relevant literature describing the evolution of spatial ability and to develop on empirically supported frameworks through a synthesis with contemporary literature. Through this, an empirically supported framework and definition will be offered and, by identifying further spatial factors which can be examined in STEM, this extended framework could enhance educational practices.

Importantly, such inquiry may support the identification of a causal relationship. Factor analysts are often described as being either lumpers or splitters depending on their tendency to focus on broad or narrow factors (McKusick 1969). As the aim of this review is to provide a heuristic framework to support educational research and practice, narrow abilities are emphasised so that the resulting framework has an increased variety of factors which can be explored in these settings. This variety has the potential to be more easily translated into practice as different factors can be examined across multiple contexts allowing for a clearer insight into how spatial ability manifests in STEM education.

\section{The Importance of Spatial Ability in STEM Education}

Having a common conception of spatial ability to act as a framework to further investigate its relationship with STEM education has the potential to support research attempting to identify the causal relationship. While determining this relationship is a significant aim within STEM education research, it is important to consider the empirical evidence which illustrates that there is a relationship to begin with. These studies typically present correlational evidence between psychometric tests of specific spatial skills and educational performance. This type of evidence continues to emerge with spatial ability now being identified as relevant to many STEM disciplines and sub-disciplines including biology (Rochford 1985; Russell-Gebbett 1985), chemistry (Small and Morton 1983; Wu and Shah 2004), physics (Kozhevnikov et al. 2007), mathematics (Cheng and Mix 2014; Pittalis and Christou 2010; Sorby et al. 
2013), computer programming (Jones and Burnett 2008), design (H. Lin 2016), engineering graphics (Marunic and Glazar 2013), geometry (Suzuki et al. 1990), and engineering (Alias et al. 2002; Sorby 2009).

While these studies illustrate the correlation in many STEM disciplines and sub-disciplines, substantial longitudinal evidence also exists cementing the importance of spatial ability within STEM in general. Shea et al. (2001) tracked 563 talent search participants (top $0.5 \%$ for their age group) who were assessed on the Scholastic Aptitude Test (SAT) and also spatial ability. Relative to the humanities and other disciplines, participants who subsequently identified mathematics or science as their favourite high school subject, earned undergraduate and graduate degrees in STEM, and ultimately ended up in a STEM career 20 years later, typically displayed higher levels of spatial ability at age 13. Additionally, spatial ability was found to account for a statistically significant amount of additional variance beyond SAT-Mathematical and SAT-Verbal in predicting these math-science criteria. Subsequently, Webb et al. (2007), with a more general sample of 1060 adolescents (top 3\% in ability), provided evidence corroborating the results of Shea et al. (2001). They found that spatial ability possessed incremental validity over both SAT scales and educational-occupational preference questionnaires over a 5-year interval for predicting favourite high school course, leisure activities relevant to STEM, college major and intended occupation. A final piece of longitudinal evidence has emerged from an analysis of the data from project TALENT (Flanagan et al. 1962). The participants from the project consisted of a random sample of the USA's high school population. The entire sample included approximately 400,000 students equally distributed between the 9th and 12th grade. Included in the tests were a number of measures designed to assess various cognitive abilities. Project TALENT also included longitudinal data taken 1, 5 and 11 years after graduation from high school (Wise et al. 1979). A number of longitudinal studies based on Project TALENT's 11-year follow-up emphasise the importance of spatial ability for accomplishments in STEM disciplines (Austin and Hanisch 1990; Gohm et al. 1998; Humphreys et al. 1993; Humphreys and Yao 2002). One specific study comparing this data to modern longitudinal findings is especially relevant (Wai et al. 2009). Wai et al. (2009) aimed to determine the extent to which spatial ability has operated consistently for decades in the prediction of educational and occupational criteria with particular emphasis on STEM disciplines. They also aimed to determine the extent to which early manifestations of exceptional spatial ability indicate the development of STEM expertise and to demonstrate how neglect of spatial ability leads to untapped pools of talent for pertinent to STEM disciplines. Their findings solidify the importance of spatial ability in STEM and illustrate its lesser importance in the humanities and social sciences. Specifically they found that:

Spatial ability is a salient psychological characteristic among adolescents who subsequently go on to achieve advanced educational and occupational credentials in STEM... [that] spatial ability plays a critical role in structuring educational and occupational outcomes in the general population as well as among intellectually talented individuals... [and that] contemporary talent searches miss many intellectually talented students by restricting selection criteria to mathematical and verbal ability measures. (Wai et al. 2009, p.827)

Lubinski (2010, p.348) generalised these results stating that 'individual differences in spatial ability contribute to learning, the development of expertise, and securing advanced educational and occupational credentials in STEM'. 
It is important to consider the results of these studies in that they do not offer an explanation as to why spatial ability has such an effect in STEM. As these studies clearly establish that it does have a critical role, there is now a need to resolve this unknown. Kirschner \& van Merriënboer (2013, p.179) argue that "research should not simply try to find out "what works" (cf. Chatterji 2005; Olson 2004) but should be aimed at explaining why particular methods help and why others do not help to reach particular goals in particular types of education under particular conditions'. The purpose of this paper is to provide a framework which can support this agenda for spatial ability and STEM education. The rationale for examining spatial factors, a construct which is defined later in this paper, is clear when considering the type of spatial factors examined in these studies. Specifically, they are associated with the mental manipulation of spatial information and often referred to as spatial skills (Uttal et al. 2013). Spatial factors can also take the form of memory-based factors and perceptual factors, which will also be described in detail later in the paper; however, these have been examined to a much lesser extent in the context of STEM education. Therefore, while there is certainty that spatial skills are important in STEM education, there is less certainty about memory and perceptual factors. If the spatial factors which are and are not correlated with STEM performance could be clearly identified, then a better understanding of exactly how spatial ability does and does not affect STEM performance could be deduced.

\section{The Origin and Evolution of Spatial Ability as a Factor of Human Intelligence}

In considering the aim of this paper as being to present an extended framework for spatial ability, and acknowledging the variety or terms associated with it, it is critical to clearly define what is meant by spatial ability and the different factors associated with it. However, to give context to these definitions, a brief overview of the origin and evolution of spatial ability as a factor of human intelligence is needed. The value of this process is apparent when considering that spatial ability has been recognised as multifaceted since its conception by Galton (1879, 1880). Galton (1879) originally conceived the idea of spatial ability; however, he described it as a visualising faculty and defined it in the context of people who hold it in a high degree stating that 'the objects in their memory are conspicuous images, they can retain them for a long time before the eye of their mind, they can dismiss or change them at will, and they can, if they please, subject them to careful examination from every side' (p.159). As he continued examining spatial ability, his definition expanded to include a wider range of cognitive actions. Specifically, he defined spatial ability as:

The capacity of calling up at will a clear, steady, and complete mental image of any object that we have recently examined and studied. We should be able to visualise that object freely from any aspect; we should be able to project any of its images on paper and draw its outline there; we should further be able to embrace all sides of the object simultaneously in a single perception, or at least to sweep all sides of it successively with so rapid a mental glance as to arrive at practically the same result. We ought to be able to construct images from description or otherwise, and to alter them in whatever way we please. We ought to acquire the power of combining separate, but more or less similar, images into a single generic one. Lastly we should learn to carry away pictures at a glance of a more complicated scene that we can succeed at the moment in analysing. (Galton 1880, p.322) 
While Galton's $(1879,1880)$ work presented the first observational evidence of spatial ability, the first quantitative evidence of its existence emerged from factor analytic studies such as those by Spearman (1927) and Thurstone (1938). Subsequent to Spearman's (1904) identification of a general intelligence, $g$, he developed his two-factor theory (Spearman 1927) and Thurstone (1938) developed his model of primary mental abilities. While Thurstone's (1938) model initially included a factor representing spatial ability which he termed Space, Spearman's model did not and only came to describe the nature of specific factors after further work by Holzinger and his colleagues (Holzinger and Harman 1938; Holzinger and Swineford 1939). The evolving understanding of the factor structure of human intelligence is illustrated chronologically in subsequent models such as those by Burt (1949), Vernon (1950), and Guilford (1966, 1967) and ultimately the use of Thurstone's factor analytic methods with various batteries of psychometric tests resulted in the identification of over 120 primary mental abilities (Carroll 1993). The empirical evidence generated throughout this process resulted in two encompassing models which describe the relationships between these factors: the Gf-Gc theory (Cattell 1943, 1963) and the three-stratum theory (Carroll 1993). A synthesis of these two theories resulted in the Cattell-Horn-Carroll (CHC) theory (McGrew 2009; Schneider and McGrew 2012), the theory which is currently recognised as the principal framework describing individual differences in the structure of human intelligence and which affords the most upto-date definition for spatial ability.

\section{A Contemporary Definition of Spatial Ability}

Since Galton's (1879) initial definition, a number of additional definitions have been used and an associated nomenclature has developed which have traditionally been contentious in the pertinent literature (Eliot and Smith 1983). This contention remains and it is therefore critical that the specific terminology associated with spatial ability and its definition is clearly presented to facilitate coherency in further research and its translation into practice. Firstly, a number of prevailing verbal definitions exist for spatial ability. For example, Lohman (1979, p.126) defines spatial ability as 'the ability to generate, retain, and manipulate abstract visual images', a definition which is routinely given in related literature (Colom et al. 2001). Gaughran (2002, p.3) provides a similar definition describing it as 'the ability to visualise, manipulate and interrelate real or imaginary configurations in space'. Sutton and Allen (2011, p.5) defined it as 'the performance on tasks that require: (a) the mental rotation of objects; (b) the ability to understand how objects appear in different positions; and (c) the ability to conceptualise how objects relate to each other in space'. Finally, Sorby (1999, p.21) defines spatial ability from an educational perspective as the 'innate ability to visualise that a person has before any formal training has occurred' and differentiates it from spatial skills which she defines as 'learned or are acquired through training'. However, 'verbal definitions of the intelligence concept have never been adequate or commanded consensus. Carroll's (1993) Human Cognitive Abilities and Jensen's (1998) The g Factor (books which will be the definitive treatises on the subject for many years to come) essentially solve the problem' (Meehl 2006, p.435). These books solve this problem as they offer definitions for intelligence factors based on empirical evidence. Therefore, it is more appropriate to define spatial ability based on the factors which load on it. As the CHC theory is currently the most contemporary framework of cognitive factors (Schneider and McGrew 2012), it is most appropriate to define spatial ability based on its factor structure within this framework. Figure 1 presents the 


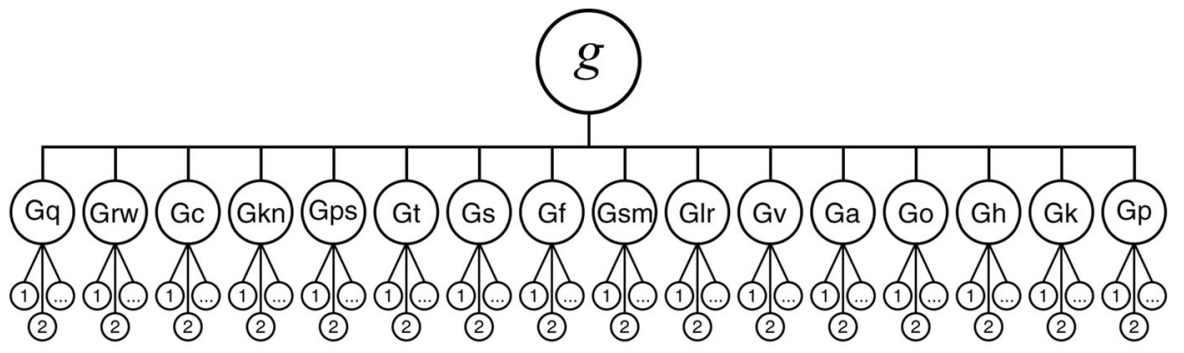

Third-order factor:

$g$ - general intelligence

Second-order factors:

Gq - Quantitative Knowledge Grw - Reading and Writing Gc - Comprehension Knowledge Gkn - Domain-Specific Knoelwdge

Gps - Psychomotor Speed
Gt - Reaction and Decision Speed
Gs - Processing Speed
Gf - Fluid Reasoning

Gsm - Short-Term Memory

Glr - Long Term Storage and Retrieva Gv - Visual Processing

Ga - Auditory Processing

Go - Olfactory Abilities

Gh - Tactile Abilities

Gp - Psychomotor Abilities

Fig. 1 The structure of the Cattell-Horn-Carroll (CHC) theory (Schneider and McGrew 2012)

structure of the $\mathrm{CHC}$ theory and illustrates its hierarchical structure. The theory contains one third-order factor, $g$, which represents Spearman's (1904) conception of a general intelligence. The theory then contains 16 second-order factors which are similar to Thurstone's (1938) primary mental abilities. Spatial ability is represented as a second-order factor; however, it is referred to as the Gv factor or visual processing. While these two terms both describe the same factor, spatial ability is its more commonly used name. The theory contains 84 first-order factors which load on the 16 second-order factors.

The Gv factor or spatial ability is defined in this theory as 'the ability to make use of simulated mental imagery (often in conjunction with currently perceived images) to solve problems' (Schneider and McGrew 2012, p.129). However, it is important to note that this definition is acting more as a description with the empirical definition being the first-order factors which load on spatial ability. In total, 11 first-order factors are shown to load on spatial ability in the CHC theory. These first-order factors are often referred to as spatial factors (McGee 1979), a term used to distinguish them from first-order factors which load on different second-order factors in the CHC theory. These can be broadly grouped into three categories. The first, spatial skills (Uttal et al. 2013) such as visualisation (Vz), are factors describing how spatial information is manipulated through actions such as mental rotation or mental cutting. The second, perceptual factors such as perceptual alternations (PN), are factors specifically describing how spatial information is perceived and encoded. The third, memory factors such as visual memory (MV), are factors describing how spatial information is stored or held in the working or short-term memory. These first-order factors are described in Table 1.

A final note on the definition of spatial ability stems from the definition offered by Sorby (1999) whereby spatial ability is differentiated between an innate and learned ability. This is especially important from an educational perspective as contemporary research agendas aspire to develop spatial ability through targeted interventions. Methodologically, it would be advantageous to identify if results are generated from participants who have engaged with such interventions or if their levels of spatial ability attainment are innate or naturally developed. However, Sorby (1999) uses the term spatial ability for when specific training 
Table 1 Spatial factors and their definitions from the Cattell-Horn-Carroll (CHC) theory

\begin{tabular}{|c|c|}
\hline Factor & Definition (Schneider and McGrew 2012) \\
\hline Visualisation (Vz) & $\begin{array}{l}\text { The ability to perceive complex patterns and mentally simulate how they might } \\
\text { look when transformed (e.g. rotated, changed in size, partially obscured) }\end{array}$ \\
\hline $\begin{array}{l}\text { Speeded rotation (spatial } \\
\text { relations) (SR) }\end{array}$ & The ability to solve problems quickly by using mental rotation of simple images \\
\hline Closure speed (CS) & $\begin{array}{l}\text { The ability to quickly identify a familiar and meaningful visual object from } \\
\text { incomplete (e.g. vague, partially obscured, disconnected) visual stimuli, } \\
\text { without knowing in advance what the object is }\end{array}$ \\
\hline Flexibility of closure (CF) & $\begin{array}{l}\text { The ability to identify a visual figure or pattern embedded in a complex } \\
\text { distracting or disguised visual pattern or array, when one knows in advance } \\
\text { what the pattern is }\end{array}$ \\
\hline Visual memory (MV) & $\begin{array}{l}\text { The ability to remember complex images over short periods of time (less than } \\
30 \mathrm{~s} \text { ) }\end{array}$ \\
\hline Spatial scanning (SS) & The ability to visualise a path out of a maze or a field with many obstacles \\
\hline $\begin{array}{l}\text { Serial perceptual integration } \\
\text { (PI) }\end{array}$ & $\begin{array}{l}\text { The ability to recognise an object after only parts of it are shown in rapid } \\
\text { succession }\end{array}$ \\
\hline Length estimation (LE) & The ability to visually estimate the length of objects \\
\hline Perceptual illusions (IL) & The ability to not be fooled by visual illusions \\
\hline Perceptual alternations (PN) & Consistency in the rate of alternating between different visual perceptions \\
\hline Imagery (IM) & The ability to mentally produce very vivid images \\
\hline
\end{tabular}

has occurred and spatial skills when it is innate. These terms are generally used with different meanings as previously discussed, so while the meanings of the words are important, it is perhaps more appropriate to describe these situations as either an innate spatial aptitude or a learned spatial ability.

Considering the number of factors within the CHC theory, a significant strength in its adoption as a conceptual framework is that it is not recognised as an absolute model (Schneider and McGrew 2012). It is therefore possible that the full remit of second- and first-order factors is yet to be uncovered. Theoretically, as humans continue to evolve as a species, it may be possible that an ultimate model is never reached. The idea that further factors may be underrepresented within the CHC theory is supported by Carroll's (1993) discussion on the existence of a number of potentially valid and unique factors such as ecological and dynamic factors which may align with spatial ability. Therefore, the following sections describe a synthesis between the well-established spatial factors from within the CHC theory with those that have emerged from empirical evidence in contemporary research. As previously noted, the perspective of splitter theorists (McKusick 1969) is being adopted in this paper and therefore factors which can be theoretically identified as being unique will be denoted as such. Each of the new factors which have been described since the creation of the $\mathrm{CHC}$ theory will be amalgamated with the current $\mathrm{CHC}$ spatial factors into an extended framework of spatial ability. This will represent the union of all uniquely described spatial factors relative to criteria described in the next section. The acknowledgement that the framework will require empirical validation as a whole after its presentation at this time is paramount. Many of the factors within it may not exist as individual factors and instead be representative in whole or in part of a currently well-established spatial factor. The framework presented in this paper is seen as an important step in determining both the structural and content validity of spatial ability thereby supporting research which examines specific spatial factors relative to STEM education. 


\section{Identifying the Unique Nature of Spatial Factors}

A substantial number of factor analytic studies describe their results in the context of spatial factors. However, the names given to these factors do not always align across studies. In addition to this, first-order factors not associated with spatial ability are often described as being related to it. For example, the factor of perceptual speed (P) has been identified as a spatial factor when visual imagery is used as the test stimulus (Pellegrino et al. 1987); however, it appears under the second-order factor of processing speed (Gs) within the CHC theory. Therefore, prior to identifying factors which could potentially be categorised as spatial factors, it is necessary to identify the nature of what a spatial factor is and what are the inclusion and exclusion criteria for being a spatial factor.

\section{Spatial Factors Are Independent of Semantic Knowledge}

Schneider and McGrew (2012, p.128) describe spatial factors as being 'sensory- and motorlinked abilities'. These factors are concerned with processing or manipulating visual or spatial stimuli and should therefore be generalizable to any context. Test instruments may require adaptations to suit varying contexts; however, their capacity to validly identify a unique factor should not be compromised in this process. This implies that semantic knowledge should not dictate a person's access to these cognitive resources. It is possible to use a combination of knowledge with spatial factors to solve problems; however, this knowledge would be a separate factor contributing to performance. The $\mathrm{CHC}$ theory acknowledges this through the second-order domain-specific knowledge (Gkn) factor which contains discipline specific firstorder factors such as the mechanical knowledge (MK) factor. A substantial amount of empirical evidence illustrates that semantic knowledge should not influence the identification of a spatial factor. Specifically within STEM education, spatial skills can become less predictive of STEM performance as learners gain discipline experience (Hambrick et al. 2012; Hambrick and Meinz 2011; Uttal and Cohen 2012). Two hypotheses emerging from these findings are that discipline expertise facilitates the circumvention of spatial skills in applied contexts, or that discipline experts utilise spatial skills not captured in traditional psychometric tests. It is anticipated that the framework presented in this article will facilitate investigations into these hypotheses by providing details of additional factors to examine from the perspective of discipline expertise.

Traditionally, the dichotomy of spatial skills and semantic knowledge has been a misconception with many researchers presenting findings as spatial factors despite the influence of knowledge. For example, Roff (1952) suggested two factors which were referred to as plotting ability (PQ) and directional thinking. Tests loading on these factors required participants to either understand coordinate systems or directional knowledge such as of compass directions (Carroll 1993). Lorenz and Neisser (1986) additionally reported three ecological spatial factors; however, a participant's familiarity with the location appears to heavily influence these factors. Lee and Bednarz (2012) discuss a list of spatial thinking components which they integrated into their Spatial Thinking Ability Test (STAT). These are derivatives of the work of Golledge (2002) and Gersmehl (2005). There is a reliance on geographic knowledge within many of these which means that not all of them can be accurately defined as spatial factors. The classification of these results as spatial factors may have been beneficial as it may have assisted in distinguishing the factors based on their tests; however, it arguably misrepresents the nature of cognitive functioning associated with the tests. 


\section{Spatial Factors Are Unique Cognitive Processes}

Within the relevant literature, there is also evidence of similarities in the definitions being given to uniquely identified spatial factors. For example, some of the factors posited by Lee and Bednarz (2012) were previously well supported within the literature (Schneider and McGrew 2012). They describe a factor concerning the capacity to comprehend orientation and direction which is an ability that forms the core of many discussions on spatial ability (Hegarty and Waller 2004; Kozhevnikov and Hegarty 2001). Many other factors proposed within the literature are also representative of already well-supported factors. Johansson (1965), for example, identified a factor in age 7 children which she called nonverbal intelligence; however, it holds a strong similarity with the visualisation $(\mathrm{Vz})$ and speeded rotation (SR) factors. Gaughran (2002) discusses five spatial factors with four of these being either encompassed within pre-existing well-supported factors or are descriptive of a whole factor. His fifth factor, dynamic imagery (SF5), described as the ability to manipulate individual elements of a component including the ability to explode and reassemble these components both requires substantial knowledge of the artefact and in addition involves the abilities outlined in the visualisation $(\mathrm{Vz})$ factor.

\section{Spatial Factors Must Represent Spatial Processes}

Another set of factors which appear within the literature that do not qualify as spatial factors are those described by Saunders (1959). He initially described a picture completion factor; however, with further research (Saunders 1960), he divided this into three individual factors. The first was a maintenance of contact factor which was ultimately eliminated as it describes a period of fixation with a visual stimulus during a test and could apply to any context. The second was an effect of uncertainty factor that was excluded as it describes a feeling of uncertainty which again could occur with any form of stimulus not just visual. Finally, a maintenance of perspective factor was excluded as it describes the perception of visual imagery which is encompassed within the visualisation ( Vz) factor. It is important to acknowledge that all of these factors were important in accounting for individual differences in performance; they just do not align with the definition of a spatial factor.

In summary, the criteria used to identify factors as spatial factors are that they are mental abilities concerned specifically with visual stimuli and which are not influenced by semantic knowledge. The current spatial factors in the CHC theory have a shared variance which has resulted in their determination as spatial factors; however, each factor also has unique variance (Carroll 1993). When synthesising spatial factors identified in contemporary research with the currently well-supported factors, the newly identified factors at a minimum had to be theoretically separable from existing factors as well as conforming to these criteria.

\section{Static and Dynamic Spatial Factors}

\section{Categorising Dynamic Spatial Ability}

One area of spatial ability which appears underrepresented in the CHC theory is that of dynamic spatial ability. The importance of this area is illustrated by Larson's (1996) acknowledgement of the poor correlation between the dynamic real world and the two-dimensional 
static tests commonly used when trying to elicit spatial factors. This idea aligns with Pellegrino et al.'s (1987) argument that the sole use of paper-and-pencil psychometric tests limits explorations of spatial ability. Early work in this area began with the use of motion picture tests designed with a military focus (Gibson 1947; Roff 1952). It has since evolved into an aspect of human intelligence research with the agenda of eliciting the scope of human cognitive abilities. This evolution has seen the development of three schools of thought in relation to dynamic spatial factors. One of which is that dynamic cognitive ability in general involves a temporal processing ability rather than a form of spatial ability. Within the literature, this debate is centred around whether prediction-motion tasks involve cognitive motion extrapolation (spatial processing) or a clocking process (temporal processing) (DeLucia and Liddell 1998). Kyllonen and Chaiken (2003) present factor analytic evidence to support the hypothesis that dynamic factors require temporal rather than spatial processing; however, this view is not universally accepted. This is possibly due to further studies identifying shared variance between tests of dynamic factors and spatial skills which are discussed below. When dynamic factors are conceived to include perceptual and memory-related abilities as well as the more traditional arrival time and speed judgement factors, it is arguable that they could be categorised as dynamic spatial abilities. This temporal capacity should not be ignored in pertinent research.

A second categorisation of dynamic spatial ability relates to the nature of the cognitive action whereby mental operations such as mental rotations are considered dynamic based on the movement of stimulus (Newcombe and Shipley 2014) and has proved particularly useful for much educational research demonstrating why frameworks of spatial ability are so important. The third categorisation considers dynamic spatial ability to involve moving stimuli and is independent of the cognitive action (Pellegrino et al. 1987). The classification of dynamic spatial ability as involving moving stimuli is the most commonly accepted. This may be associated with biological evidence identifying neurons as responsive to selective stimuli (Groh 2014). For example, Hubel and Wiesel (1959) identified single neurons as responsive to stimuli orientation while Haag and Borst (2004) describe specific motion sensitive neurons.

\section{Evidence Dissociating Dynamic and Static Spatial Ability}

Some of the pioneering work in establishing dynamic spatial factors was conducted by Roff (1952) through the use of a factor analysis on motion picture tests from which he identified a factor referred to as movement time. There were six variables loading on this factor in his factor analysis. Five were designed to measure the ability to identify movement direction, minimal movement, to judge destination, to record simultaneous movement and to integrate partial impressions observed through a moving slot into a single visual scheme or pattern. The sixth variable which loaded on the factor was a static variable designed to measure objectivity of perception. While not classified at the time as dynamic spatial ability, Roff's (1952) tests appear to be measuring similar factors to those in the more contemporary studies.

Subsequent to the work of Roff (1952) and Gibson (1947), the concept of dynamic spatial ability was further investigated by Hunt and Pellegrino. With colleagues, they examined dynamic spatial factors through the use of computer-based tests, which were tested for construct validity, through a factor analysis with static spatial factors (Hunt et al. 1988; Pellegrino and Hunt 1989; Pellegrino et al. 1987). This work provided a basis for two more factor-analytic studies (Contreras et al. 2003; D’Oliveria 2004) which were again carried out to 
determine if dynamic spatial ability was distinguishable from static spatial ability. Both studies used exploratory and confirmatory factor analyses with multidisciplinary cohorts. The results from each of these studies support the distinction between static and dynamic spatial ability and propose independent dynamic factors which are distinct from static factors. Contreras et al. (2003) identified factors concerned with the ability to direct moving stimuli to a set destination and D'Oliveria (2004) discussed factors associated with arrival time and intercept judgement. Taking cognisance of Larson's (1996) work, it should be recognised that dynamic spatial factors involve different mental operations to static spatial factors, and through an amalgam of the evidence presented by studies such as those by Roff (1952), Contreras et al. (2003) and D'Oliveria (2004), it is suggested that dynamic factors involving directional judgement, speed judgement and movement detection be afforded recognition.

While these studies examine factors entirely separate from validated static spatial factors, the potential for validated static spatial factors to be also considered as dynamic spatial factors has not yet been explored. The capacity exists to explore visual memory (MV), spatial scanning (SS), serial perceptual integration (PI) and perceptual alternations (PN) as dynamic factors as both static and dynamic stimuli can be created for each. Considering this, it is suggested that dynamic alternatives to these factors be considered as hypothetically unique factors until the potential differences in cognitive processes are examined to make explicit determinations.

\section{Mental Rotation and Spatial Orientation Spatial Factors}

In conjunction with dynamic spatial factors, a number of static factors are described within the literature which do not rely on semantic knowledge and are uniquely dissociable from factors already identified within the $\mathrm{CHC}$ theory. One area where this is apparent relates to factors concerning mental rotation. A substantial degree of research which has uncovered the correlation between spatial ability and STEM education has done so through the use of psychometric tests requiring mental rotation. In light of this, uncovering the unique existence of factors associated with mental rotations is of significant importance. In particular, this refers to the differentiation between factors involving the mental rotation of a stimulus and of the self. Psychometric tests which have identified such factors include the Card Rotations Test (CRT) (Ekstrom et al. 1976), the Purdue Spatial Visualisation Test: Visualisation of Rotations (PSVT:R) (Guay 1977) and the Perspective Taking Spatial Orientation Test (PTSOT) (Hegarty and Waller 2004; Kozhevnikov and Hegarty 2001). Considering the nature of these tests, they suggest factors including the speeded rotation of two-dimensional stimuli quickly (CRT), the mental rotation of more complex three-dimensional stimuli with less of a time constraint (PSVT:R) and the capacity to mentally take a different perspective in space to perceive a stimulus from a different viewpoint (PTSOT).

\section{Evidence Dissociating Mental Perspective Taking and Mental Rotation Factors}

Ultimately, the discussion concerning the uniqueness of these factors relates to the continuing discussion regarding the existence of a spatial orientation (SO) factor. McGee (1979) summarises a variety of definitions found within the literature for this factor whereby it is apparent that spatial orientation (SO) is typically concerned with the perception of visual stimuli from multiple perspectives in space. The status of spatial orientation ( $\mathrm{SO}$ ) as a perspective taking 
factor and of factors concerning the mental rotation of a stimulus continues to be an iterative topic. Despite many researchers identifying spatial orientation (SO) as a core factor of spatial ability (Bodner and Guay 1997; Linn and Petersen 1985; McGee 1979; Smith 1964), it is currently not recognised in the $\mathrm{CHC}$ theory as an independent factor due to the difficulty in differentiating it from mental rotation factors. Hegarty and Waller (2004) posit that this may be due to a considerable shared variance between perspective taking and mental rotation factors as they rely on many common cognitive processes. Hegarty and Waller (2004) designed a valid measure of perspective taking ability and through confirmatory factor analysis have shown evidence to support the uniqueness from mental rotation factors. Their work is further supported by a meta-analysis conducted by Wang et al. (2014) which provides evidence for two forms of spatial ability: small-scale spatial ability and large-scale spatial ability. Smallscale spatial ability involves allocentric spatial transformation which requires a person to perceive the relationships between objects. Large-scale spatial ability involves egocentric spatial transformation which requires a person to perceive the relationship between themselves and the object. This has been previously referred to as spatial orientation (Kozhevnikov and Hegarty 2001). The distinction between perspective taking and mental rotation factors provides merit for further exploration into a spatial orientation (SO) factor and as a result this factor deserves independent recognition. Large-scale spatial ability also describes that ability to learn and navigate environmental information and routes. However, while a perspective-taking ability can be identified as a unique factor, the construct of large-scale spatial ability is more difficult to describe in this way as there is a significant body of evidence illustrating its association with perspective taking, memory and spatial skills such as spatial relations and visualisation (Allen et al. 1996; Fields and Shelton 2006; Hegarty et al. 2006; Ishikawa and Montello 2006; Kozhevnikov et al. 2006; Weisberg et al. 2014). Therefore, while the construct of large-scale spatial ability is of significant importance, it is perhaps better thought of as an amalgam of first-order factors when considered through the lens of environmental learning.

\section{Evidence Dissociating Two-Dimensional and Three-Dimensional Mental Rotation Factors}

There is further ambiguity in the existence of a spatial relations factor. While currently not included as an individual factor in the CHC theory after being replaced by a speeded rotations (SR) factor (McGrew and Evans 2004; Schneider and McGrew 2012), spatial relations deserves additional research in order for a comprehensive decision to be made regarding its existence. Harle and Towns (2010) summarise the discussion regarding the classification of mental rotation factors concluding with spatial relations being considered as the primary mental rotations factor. In addition to this, Moreau (2013) demonstrated a potential yet differentiating link between speeded rotation (SR) and spatial relations through spatial ability training. Cognitive training associated with spatial relations improved both factors whereas training associated with speeded rotation (SR) improved only itself. Considering the geometry involved, a hierarchical relationship is posited to exist between these factors. This hypothesis would align with the speed-power or simple-to-complex continuum described by Larson (1996) with speeded rotations residing at the speed end of the continuum and spatial relations being located at the power end.

However, disagreement regarding the uniqueness of a spatial relations factor persists as evidenced through its non-existence in the current CHC theory. Tests such as the PSVT:R (Guay 1977) which requires the rotation of complex geometries with less of a time constraint 
should be examined beside established tests of visualisation (Vz) such as the Foam Board Test or the Paper Folding Test and tests of speeded rotation (SR) such as the CRT and the Cube Comparisons Test (Ekstrom et al. 1976) to generate further insight which may inform this discussion. It is possible that spatial relations, considered here to represent the mental rotation of complex three-dimensional geometry under relatively untimed conditions, is an indicator of the visualisation $(\mathrm{Vz})$ factor. Ultimately, there is a hypothesised relationship between speeded rotation (SR) and spatial relations as they both involve object-based rotations, with spatial orientation (SO) being differentiated by its reliance on egocentric and allocentric reasoning (Klatzky 1998).

\section{Imagery and Perceptual Illusion Spatial Factors}

\section{Evidence of Multiple Imagery Factors}

Another area within spatial ability research where significant efforts have been made to uncover its full remit is the area of human perception. For example, the imagery (IM) factor which 'refers to the mental depiction or recreation of people, objects, and events that are not actually present' (Finke and Freyd 1994, p.561) is represented as a single factor in the CHC theory. However, Burton and Fogarty (2003) carried out an extensive factor analytic study focusing on fully determining this factor structure. Carroll (1993) noted that at the time of his review, the imagery factor was not clearly defined and following his recommendation for further investigation into the factor, Burton and Fogarty (2003) identified three unique imagery factors which they posited as imagery quality, imagery speed and imagery self-report. The imagery quality and imagery speed factors reflect research suggesting the imagery may be a 'multidimensional construct characterised along the dimensions of generation, vividness, clarity, controllability, transformation and/or maintenance (Kosslyn 1981; Poltrock and Agnoli 1986)' (McGrew and Evans 2004, p.16). The imagery self-report factor, however, is a measure of a person's belief of their capacity to generate vivid mental images and is therefore not objective or a valid measure of the imagery factor. It is conceivable that tests which loaded on this factor do not directly measure a cognitive ability but rather a perception of ability. McGrew and Evans (2004) suggest this may be a method factor as it was the only factor defined in the study by participants' self-reports.

\section{Evidence of Multiple Perceptual Illusions Factors}

Another position on visual perception relates to the perceptual illusions (PI) factor. Where imagery (IM) describes the capacity to generate a mental image, perceptual illusions (PI) describes the ability to not be fooled by illusions when encoding visual information. Currently, perceptual illusions (PI) is included as a single factor within the CHC theory; however, Coren et al. (1976) suggest five individual factors based on factor-analytic results. In their study, they created valid measures of illusions based on their geometry and how they affect people. Carroll (1993, p.357) described this work as a 'major factor-analytic study' and acknowledged the potential for multiple illusionary factors as a result. The findings suggest that individuals differ not only in the degree they are affected by visual illusions but also by which illusions affect them and include shape and direction illusions, size contrast illusions, overestimation illusions, underestimation illusions and frame of reference illusions. Based on these categories, 
investigations have been undertaken aiming to determine the cause for illusory effects on the perceptual system with Howe and Purves (2005) illustrating empirically how the frequency of geometry within the physical world aligns with illusory stimuli.

\section{An Extended Framework of Spatial Ability: A Synthesis of Contemporary Research}

Synthesising the empirical evidence and arguments offered above, it is arguable that the current remit of spatial ability within the CHC theory and its definition (Table 1) could be broadened to represent a more comprehensive range of cognitive factors. Table 2 offers a summary of factors which are currently not explicitly represented within the CHC theory and provides the definitions given by the relevant researchers where available or tentative definitions where factors are hypothetical.

The union of the spatial factors currently contained within the CHC theory (Table 1) and the spatial factors emerging from contemporary literature (Table 2) suggests that the remit of spatial ability could theoretically contain 25 factors. Some of these factors such as visualisation (Gv) are known to be more powerful in their representation of spatial ability (Carroll 1993; Schneider and McGrew 2012). Therefore, the new factors within this framework merit investigation to explicitly quantify their representativeness. Additionally, a number of potential relationships between spatial factors meriting further research emerge through this amalgam. Figure 2 illustrates a conceptual diagram of this extended framework of spatial ability identifying these relationships. The importance of the newly identified factors in the context of STEM education and the relationships between factors will be discussed in more detail in the next section. The inclusion of the term visual processing at the top of the framework with spatial ability is to reflect its position as the second-order factor within the CHC theory. Both terms represent the same cognitive factor.

\section{The Significance of the Extended Framework in STEM Education}

\section{The Importance of Spatial Ability in Non-STEM Disciplines}

It is important to consider the potential significance of this framework for learning in general as well as in STEM education. As previously discussed, two theories were synthesised to create the CHC theory. One of these, the Gf-Gc theory (Cattell 1943, 1963) specifically differentiates between the two second-order factors of fluid intelligence (Gf) and crystallised intelligence (Gc). Fluid intelligence (Gf) is defined as 'the use of deliberate mental operations to solve novel problems (i.e., tasks that cannot be performed as a function of simple memorization or routine)' (Primi et al. 2010, p.446). Crystallised intelligence (Gc) is defined as 'accessible stores of knowledge and the ability to acquire further knowledge via familiar learning strategies' (Wasserman and Tulsky 2005, p.18). Neuroscientific evidence has shown that the visualisation (Vz) factor of spatial ability is a component of fluid intelligence (Gf) (Ebisch et al. 2012). Additionally, fluid intelligence (Gf) has been identified as a causal factor in general learning as it supports the acquisition of knowledge and skills (Kvist and Gustafsson 2008; Primi et al. 2010). These relationships allow for the hypothesis to be drawn that visualisation $(\mathrm{Vz})$ may have a role in learning in general, and as it is the strongest predictor 
Table 2 Summary of factors associated with spatial ability currently not represented within the CHC theory

Factor Definition

Spatial orientation $(\mathrm{SO})$

Spatial relations

Imagery quality

Imagery speed

Shape and direction illusions

Size contrast illusions

Overestimation illusions

Underestimation illusions

Frame of reference illusions

Dynamic visual memory

Dynamic serial perceptual integration

Dynamic spatial scanning

Dynamic perceptual alternations

Directional judgement

Speed judgement

Movement detection
The comprehension of the arrangement of elements within a visual stimulus pattern, the aptitude to remain unconfused by the changing orientations in which a spatial configuration may be presented and an ability to determine spatial orientation with respect to one's body (McGee 1979, p.897)

The ability to solve problems by using mental rotation of complex images in a relatively untimed situation

The ability to generate a mental image, add and/or subtract detail from the image, rotate, maintain and transform the image in specified ways (Burton and Fogarty 2003, p.310)

The efficiency of those processes involved in the generation, maintenance and transformation of mental representations (Burton and Fogarty 2003, p.311)

This grouping predominantly includes distortions in apparent shape, parallelism and collinearity, which seem to arise in patterns with numerous intersecting line elements. The Poggendorff, Wundt and Zoellner illusions are characteristic of this class (Coren et al. 1976, p.134)

This classification... represents those illusory distortions in which the apparent size of an element appears to be affected by the size of other elements that surround it, or form its context. The Delboeuf, Ebbinghaus, Jastrow and Ponzo illusions are characteristic of the illusions on this factor (Coren et al. 1976, p.134)

[This] grouping [is] on the basis of the behavioural manifestation that does not immediately suggest any underlying mechanism but suggests a pattern of interrelationship. The illusions that show the highest loadings on this factor include all the apparently longer versions of the Mueller-Lyer illusion, both parts of the Baldwin illusion, the apparently longer segment of the horizontal-vertical illusion and the apparently longer segment of the Oppel-Kundt illusion (Coren et al. 1976, p.134)

[This factor] includes most of the apparently shorter segments of the Mueller-Lyer illusion, the apparently shorter segment of the Oppel-Kundt and the horizontal-vertical illusions, it seems to be a factor that is the complement to [overestimation illusions], representing predominantly underestimations of linear extent (Coren et al. 1976, p.135)

[This factor involves] the comparison of an element to its global frame of reference... illusions like the rod-and-frame ought to fall into this classification (Coren et al. 1976, p.135)

The ability to remember complex dynamic images over short periods of time (less than $30 \mathrm{~s}$ )

The ability to recognise a dynamic object after only parts of it are shown in rapid succession

The ability to visualise a path out of a dynamic maze or a field with many obstacles

Consistency in the rate of alternating between different visual perceptions of a dynamic stimulus

[This factor is] necessary to account for performance of tasks involving prediction of directions (Colom et al. 2001, p.905)

[This factor is] necessary to account for performance of tasks involving prediction of arrival times of moving objects (Colom et al. 2001, p.905)

The ability to detect barely visible movement of an object and to determine the direction of this movement (Roff 1952, p.4).

of spatial ability, this provides some evidence to infer that spatial ability may be related to nonSTEM disciplines in this way. However, it is still important to consider the longitudinal evidence illustrating the lack of importance of spatial ability in the humanities and social sciences relative to verbal abilities (Wai et al. 2009). Currently, there is insufficient evidence to infer further significance for spatial ability outside of STEM. However, this difference in the 


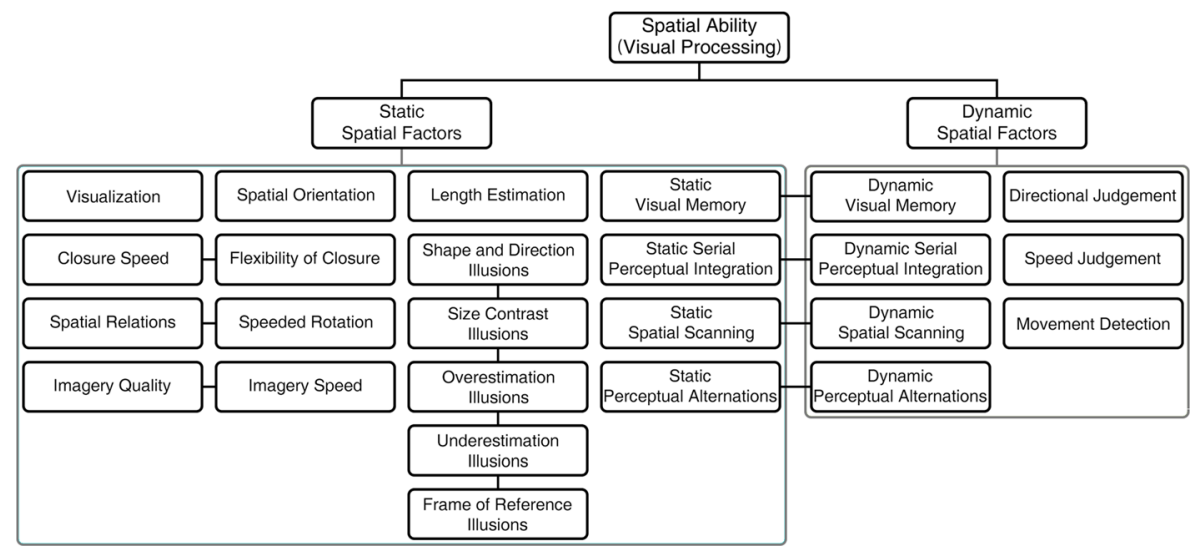

Fig. 2 Theoretical extended framework of spatial ability

importance of spatial ability between STEM and non-STEM disciplines indicates a difference in cognitive factors associated with educational performance between these areas. Understanding this difference has the potential to aid in identifying why spatial ability is important in STEM. This is analogous to a way in which the framework presented in this paper can be beneficial. By scientifically identifying which factors are associated with specific STEM disciplines and to what extent, common or underlying general cognitive processes could be identified to support the determination of a causal theory.

\section{Visualisation, Mental Rotations and Perspective-Taking Spatial Factors}

The specific spatial factors which are known to be important in STEM education are typically spatial skills. The visualisation (Vz) factor is known to be the highest loading factor on spatial ability (Carroll 1993) and 'almost all of the studies showing [spatial ability] has predictive validity in forecasting important outcomes use measures of visualization as a proxy for [spatial ability] as a whole' (Schneider and McGrew 2012, p.129). The visualisation (Vz) factor in particular has been used in most longitudinal studies identifying the importance of spatial ability in STEM (e.g. Lubinski 2010; Wai et al. 2009). The evidence illustrating the importance of the visualisation factor in STEM education is particularly strong; however, the reason for its importance remains unknown. It may be that the nature of cognitive activity which represents the factor, complex three-dimensional geometric manipulation, is similar to the cognitive activity typically engaged with in STEM education. Alternatively, it may be due to its relationship with fluid intelligence (Gf) with that being the causal factor. Furthermore, the exact nature of this factor requires further specification. There are many psychometric tests which have been used as indicators of this factor. These tests typically include paper folding, surface development, mental cutting and mental rotations. In paper folding, surface developments and mental cutting, there is a commonality in that the stimulus undergoes a transformation where the geometry changes; however, this is not the case in mental rotations as the geometry does not change but rather its position does. Tests of each of these skills have been shown to correlate strongly with STEM performance (Harris et al. 2013; Lin and Chen 2016; Olkun 2003; Sorby 2009). There are different strategies which can be used in these tests (e.g. Heil and Jansen-Osmann 2008); however, this difference is foundational to the argument that a spatial relations factor exists separately from the visualisation $(\mathrm{Vz})$ factor. There is factor 
analytic evidence that mental rotations is a separate factor (Harris et al. 2013) and the framework presented in this paper acknowledges it as a separate factor, but there is undoubtedly a strong relationship between them which is why their dissociation is not yet conclusive. What is conclusive is that they are all fundamentally important in STEM.

There is a clear relationship between spatial relations and speeded rotation (SR) as both involve mental rotations but with three-dimensional and two-dimensional geometry, respectively. This is evident in the current status of the CHC theory and has been empirically confirmed by Moreau (2013). While a spatial relations factor has a substantial amount of evidence showing it is important in STEM, the evidence for a speeded relations factor is less conclusive. Wu and Shah (2004) describe how mentally rotating two-dimensional geometry could be important in chemistry education as students have to do this when identifying polymers. However, the lack of cognitive power associated with this task brings the significance of this factor into question. This lack of cognitive power is likely the reason why speeded rotation (SR) is typically examined in the context of children in STEM subjects. Cheng and Mix (2014) and Hawes et al. (2015) examined the effect of two-dimensional mental rotation training on mathematics performance in 6- to 8-year-olds. Cheng and Mix (2014) implemented a mathematics post-test directly after the training and found statistically significant gains in performance relative to a pre-test. Hawes et al. (2015) used a different training intervention, still focusing on two-dimensional mental rotations, but the post-test was conducted a week after the intervention and no improvement was observed. They did find statistically significant correlations between pre-test measures of two-dimensional mental rotations and mathematics problems ranging from $r=0.40$ to 0.63 . Hawes et al. (2015) posited that the gains found by Cheng and Mix (2014) were due to a priming effect as the mathematics problems were similar to the two-dimensional mental rotations rather than an increased level of speeded rotations (SR) ability; however, they acknowledge further research is needed to determine the relationship more explicitly.

There is a posited shared variance between mental rotations and spatial orientation (SO) (Hegarty and Waller 2004) and arguably the proposed framework should represent links between these factors. As the relationship is not yet fully established, it is premature to assume one exists especially considering the large amount of research aimed at determining its dissociation from mental rotations. In terms of eliciting its significance in STEM, there has been little research conducted in comparison. Hodgkiss et al. (2018) identified small to moderately sized positive partial correlations between spatial orientation and science education performance in 7- to 11-year-olds. Additionally, Carbonell Carrera et al. (2011) found a statistically significant gain in spatial orientation ability in higher level engineering students after engagement in geographic and geospatial activities. However, if there is a shared variance with mental rotations, this could account for the correlations. Considering the results from Carbonell Carrera et al. (2011), it is conceivable that spatial orientation would be important in design-based aspects of STEM, particularly in relation to the built environment where there is a need to imagine structures in position from various viewpoints.

\section{Speed Judgement, Directional Judgement and Movement Detection Spatial Factors}

The dichotomy of static and dynamic spatial factors exists at a categorical level in the presented framework to differentiate broadly between the two types of spatial factors. To date, little research has examined dynamic spatial factors in the context of STEM education, yet theoretically they have a clear relevance. The three purely dynamic factors included in the 
framework are directional judgement, speed judgement and movement detection. Similar to the factors in the previous section, directional judgement and speed judgement could be classified as spatial skills, whereas movement detection is more aligned with the perceptual spatial factors discussed later. As previously mentioned, when considering the importance of these factors, cognisance should be given to Larson's (1996) assertion that we live in an inherently dynamic world and therefore dynamic spatial factors may be more aligned with the nature of human activity. This is particularly true of STEM education. In science, the conduction of experiments for example often involves working with and observing moving components or artefacts, and in technology and engineering moving components are very prevalent. Specifically related to when this is the case, Kyllonen and Chaiken (2003) have shown that dynamic spatial factors involving arrival time are significantly important in psychomotor tasks involving control precision, multilimb coordination, rate control and response orientation. This study directly aligns with the speed judgement factor and is tangentially related to directional judgement as well. From this, the relationship with movement detection can be posited in tasks requiring psychomotor precision such as in the craft aspects of STEM as the ability to detect minimal movement would allow for greater precision. A second way in which this group of factors has been demonstrated as important in STEM learning refers to the type of mental models which learners are frequently required to construct. In all STEM disciplines, learners regularly read text describing dynamic movement. In mathematics or physics, for example, this can be seen in the study of velocity, and in technology and engineering, this can be seen when problems involve mechanisms. Sanchez and Wiley (2014) have shown in a study on geoscientific text comprehension that dynamic spatial ability, particularly associated with speed and directional judgement, was especially relevant when learners had to read text describing movement and an animation of the movement was not provided.

\section{Imagery, Closure, Illusory and Length Estimation Spatial Factors}

The preceding sections described spatial skills, both static and dynamic, and were of particular known importance to STEM education or were clearly related to factors of known importance. Perceptual spatial factors such as movement detection can also be seen as important but often as they underpin the mental operations involved in spatial skills. The imagery (IM) factor is a clear example. Directly, it has been posited as fundamental to geometry and the study of human anatomy (Thompson et al. 2009), but as this factor describes the capacity to form a vivid mental image, it is likely related to all spatial skills and memory-related factors. While not explicitly examined in the context of STEM learning, the imagery (IM) factor is likely to be important for all aspects of learning, in all aspects of education not just STEM, where visual thinking is critical. In terms of its separation between quality and speed as shown in the presented framework, the quality factor is likely to be of greater significance as in most if not all educational scenarios, the time difference in this capacity for learners will be situationally negligible.

Two perceptual-based factors which are closely linked are the flexibility of closure (CF) and closure speed (CS) factors as both involve the identification of a stimulus. Höffler (2010) notes how these factors have been largely neglected but that it might be worthwhile to consider them in future studies. Baynes (1992, p.17) postulated the potential for these perceptual spatial factors to be aligned with design activity in STEM through his recognition of a direct link between the perceptual predisposition and the design output of human societies, as the Gestalt principles of 'proximity, sameness, closure, symmetry and contrast (amongst others) are 
qualities that can be seen in buildings and products from all cultures'. Wu and Shah (2004) describe how the flexibility of closure (CF) factor is related to chemistry education. As the factor is concerned with identifying visual information when embedded in distracting information, they describe how this ability is important when interpreting synthesis schemes of chemical structures. Bodner and McMillen (1986) found statistically significant weak correlations between the flexibility of closure (CF) factor and an introductory organic chemistry course. Subsequently, Carter et al. (1987) found similarly weak but statistically significant correlations between the flexibility of closure (CF) factor and general chemistry performance. These results indicate that at least in chemistry, or perhaps more generally to areas of STEM where information has to be interpreted when embedded in distracting visual information such as in diagrams of chemical structures, this factor is significant but not to a high degree.

The relationship between STEM and closure speed (CS) is likely to be similar in that the factor also describes the identification of a stimulus; however, in this circumstance, it is when that stimulus is partially incomplete. This factor concerns the access of visual information from long-term memory (Höffler 2010) and as such is likely related to all educational disciplines in the same way. An example of its potential relevance can be seen in problem solving where closure speed (CS) is involved in a learners' search process of their long-term memory for schema associated with that problem. As such, while it may prove to have a statistically weak association with STEM, it is likely to have a very fundamental role.

The five illusory spatial factors merit separation in the framework to accurately depict their empirically derived factor structure (Coren et al. 1976); however, the significance of individual illusory factors is likely to be similar. Coren and Porac (1987) showed that illusions of linear extent were directly proportional to spatial ability whereas the illusions associated with direction and area have an inverse relationship. Coren et al. (1976) posit different causal mechanisms to be associated with each group of illusions. Similar to the closure factors as these involve perception, their significance likely lies in mental activity which underpins spatial skills. It is unlikely that the role of illusory factors is directly observable or causal.

The length estimation (LE) factor, which describes the ability to accurately judge spatial distances without the aid of a measurement instrument, does represent a reliable individual difference, but it is likely to be the least important in terms or STEM education and possibly any discipline. Carroll (1993, p.356) described it as a factor which is 'practically valueless for assessing or predicting any behaviour of importance' due to the availability of measurement instruments which make this ability unnecessary. Despite its likely lack of importance, it is still worthwhile to include this factor in frameworks of spatial ability to ensure accuracy in its depiction.

\section{Perceptual Integration, Spatial Scanning, Perceptual Alternations and Memory Spatial Factors}

While the two categories of static and dynamic spatial factors are presented in this framework, some factors can be assessed with both types of stimulus. As a result, they may theoretically be considered as dichotomous or bifurcated factors where the category of the factor is determined by the type of stimulus. The factors which could be examined with both static and dynamic stimuli include serial perceptual integration (PI), spatial scanning (SS), perceptual alternations (PN) and visual memory (MV), the first three of which are perceptual factors similar to those described in the previous section. In relation to the serial perceptual integration (PI) factor, Carroll (1993) noted how traditionally this was difficult to assess due to technological limitations. This was due to the factor describing the perception of visual stimuli for very 
short periods of time, for example $10 \mathrm{~ms}$. Based on the short timespan involved, he posited that it may refer to an aspect of iconic memory. Similar to the previously described perceptual factors, this would suggest its importance in education goes beyond STEM. To consider it specifically within STEM education, it likely underpins some of the spatial skills, particularly the dynamic spatial skills as iconic memory has a critical role in the perception of movement. Carroll's (1993) alternative hypothesis was that this factor represented another form of the closure speed (CS) factor due to the similarity in tests. There was no existing evidence for him to use to evaluate this hypothesis.

The spatial scanning (SS) factor describes the ability to quickly and accurately scan a visual field such as when tracing a path through a maze. There is no evidence for its application in STEM education. Again, as a perceptual factor, it likely underpins some of the important spatial skills. This is evidence, as Carroll (1993) notes, that the tests which relate to it often load on the visualisation (Vz) factor. Additionally, Tversky (2005) postulates that mental scanning may be involved in tasks such as hitting a ball in baseball or tennis. The need for speed and directional judgement in such tasks may mean that spatial scanning is important to these dynamic spatial skills and then indirectly to STEM education.

The perceptual alternations (PN) factor involves the ability to alternative between different visual perceptions of a stimulus. Similar to how the dynamic spatial skills have been shown to be important for comprehending text describing motion, it is possible that this factor is important when comprehending diagrams. One of the most commonly used stimuli to test this factor is the Necker cube. Many diagrams in STEM problems are represented as line diagrams similar to the Necker cube, and this factor may aid learners in interpreting them.

The final spatial factor, visual memory (MV) is the only memory-based spatial factor in the framework although represented twice to reflect its capacity to be measured with both static and dynamic stimuli. There is research which illustrates the relationship between the working memory, spatial ability and general problem solving (Bühner et al. 2008) and also between working memory and science (Yuan et al. 2006) and mathematics (De Smedt et al. 2009; Raghubar et al. 2010) education. It is important to note that these studies are not differentiating between the different components of the working memory such as the visuospatial sketchpad and the phonological loop (Baddeley 2000). Van de Weijer -Bergsma et al. (2015) have examined working memory in mathematics while specifically differentiating between the visual-spatial and verbal components of working memory. Their findings illustrate that as grade level increased, the predictive capacity of visual-spatial working memory declined while the predictive capacity of verbal working memory increased.

\section{The Implications and Operationalisation of the Extended Framework in STEM Education}

It is not the agenda of this paper to propose a finalised model of spatial ability as more factors may be uncovered in future research. Instead, the aim is to offer a theoretical foundation to support further inquiry into the relationship between spatial ability and STEM education. It is posited that further factors exist, perhaps currently under investigation or not yet conceived and explored, which in time will be recognised as unique factors. It is hoped that such work can be synthesised with the framework presented in this article to further support research and practice concerning spatial ability. Additionally, further work may refute the unique existence of some of the factors presented in this paper. This would 
also be a welcome contribution as more explicitly refining the remit of spatial factors can further aid in establishing why spatial ability has such an impact on STEM educational performance and retention. In addition, this framework only represents spatial factors associated with internal thinking. In STEM practice, the externalisation of thinking through modelling is of critical importance (Seery 2017).

Considering the framework presented within this paper, a number of critical considerations emerge relative to the identification of further spatial factors. These include recognising the categorical dichotomy of static and dynamic spatial factors, acknowledging the differences between spatial skills, perceptual factors and memory factors, and considering the influence of knowledge on the manifestation of spatial skills. From a methodological perspective, as further spatial factors are posited, the use of factor analytic methods to determine their uniqueness will become more difficult as the number of tests participants will have to take could result in fatigue or a loss of motivation (Floyd 2005). Therefore, it is envisioned that alternative approaches may become more appropriate in determining the uniqueness of factors.

Identifying further spatial factors will further progress the agenda of developing a cognitive map of the human mind (Sternberg 2000). While numerous implications extend from this, specifically within the context of STEM the provision of a more comprehensive conceptual framework can be used to aid in determining the causal relationship between spatial ability and STEM educational performance (Lubinski 2010; Wai et al. 2009). In the same context as eliciting a causal relationship, the framework also permits the use of psychometric testing to create a profile describing the cognitive strengths and weaknesses of STEM students. The use of cognitive profiles such as this has been shown to account for significantly more variance in academic achievement than a correlation (Letteri 1980). It would also facilitate the scientific refinement of spatial ability interventions in STEM which have proven to have significant positive effects over the last number of decades (Uttal et al. 2013).

Substantial research has established that spatial skills are malleable and that they respond positively to training, life experiences and educational interventions (Baenninger and Newcombe 1989; Terlecki et al. 2008; Uttal et al. 2013; Wright et al. 2008). While many interventions have been created which aspire to enhance spatial ability (e.g. Dimitriu 2015; July 2001; Sorby 2009; Sorby and Baartmans 2000), perhaps the most widely adopted is the intervention created by Sorby (Sorby 1999, 2009; Sorby and Baartmans 1996, 2000). Giving cognisance to how having lower levels of spatial ability can negatively impact novice STEM learners, Sorby's intervention was designed specifically to support students with low spatial ability. However, until the causal relationship between spatial ability and STEM education is uncovered, there is a limitation on the capacity to scientifically refine and optimise the efficacy of cognitive interventions and by association, STEM educational practice.

Open Access This article is distributed under the terms of the Creative Commons Attribution 4.0 International License (http://creativecommons.org/licenses/by/4.0/), which permits unrestricted use, distribution, and reproduction in any medium, provided you give appropriate credit to the original author(s) and the source, provide a link to the Creative Commons license, and indicate if changes were made.

\section{References}

Alias, M., Black, T., \& Gray, D. (2002). Effect of instructions on spatial visualisation ability in civil engineering students. International Education Journal, 3(1), 1-12. 
Allen, G., Kirasic, K., Dobson, S., Long, R., \& Beck, S. (1996). Predicting environmental learning from spatial abilities: An indirect route. Intelligence, 22(3), 327-355.

Austin, J., \& Hanisch, K. (1990). Occupational attainment as a function of abilities and interests: A longitudinal analysis using project TALENT data. The Journal of Applied Psychology, 75(1), 77-86.

Baddeley, A. (2000). The episodic buffer: A new component of working memory? Trends in Cognitive Sciences, 4(11), 417-423.

Baenninger, M., \& Newcombe, N. (1989). The role of experience in spatial test performance: A meta-analysis. Sex Roles, 20(5-6), 327-344.

Baynes, K. (1992). Research into primary design and technology. In B. Archer, K. Baynes, \& P. Roberts (Eds.), The nature of research into design and technology education. Design curriculum matters: Occasional paper no. 1 (pp. 15-21). Leicestershire: Loughborough University.

Bodner, G., \& Guay, R. (1997). The Purdue visualization of rotations test. The Chemical Educator, 2(4), 1-17.

Bodner, G., \& McMillen, T. (1986). Cognitive restructuring as a first step in problem solving. Journal of Research in Science Teaching, 23(8), 727-737.

Burt, C. (1949). The structure of the mind. British Journal of Educational Psychology, 19(3), 176-199.

Burton, L., \& Fogarty, G. (2003). The factor structure of visual imagery and spatial abilities. Intelligence, 31(3), 289-318.

Bühner, M., Kröner, S., \& Ziegler, M. (2008). Working memory, visual-spatial-intelligence and their relationship to problem-solving. Intelligence, 36(6), 672-680.

Carbonell Carrera, C., Saorín Pérez, J. L., de la Torre Cantero, J., \& Marrero González, A. M. (2011). Engineers' spatial orientation ability development at the European Space for Higher Education. European Journal of Engineering Education, 36(5), 505-512.

Carroll, J. (1993). Human cognitive abilities: A survey of factor-analytic studies. New York: Cambridge University Press.

Carter, C., LaRussa, M., \& Bodner, G. (1987). A study of two measures of spatial ability as predictors of success in different levels of general chemistry. Journal of Research in Science Teaching, 24(7), 645-657.

Cattell, R. (1943). The measurement of adult intelligence. Psychological Bulletin, 40(3), 153-193.

Cattell, R. (1963). Theory of fluid and crystallized intelligence: A critical experiment. Journal of Educational Psychology, 54(1), 1-22.

Chatterji, M. (2005). Evidence on "what works": An argument for extended-term mixed-method (ETMM) evaluation designs. Educational Researcher, 34(5), 14-24.

Cheng, Y., \& Mix, K. (2014). Spatial training improves children's mathematics ability. Journal of Cognition and Development, 15(1), 2-11.

Colom, R., Contreras, M. J., Botella, J., \& Santacreu, J. (2001). Vehicles of spatial ability. Personality and Individual Differences, 32(5), 903-912.

Contreras, M. J., Colom, R., Hernández, J. M., \& Santacreu, J. (2003). Is static spatial performance distinguishable from dynamic spatial performance? A latent-variable analysis. The Journal of General Psychology, $130(3), 277-288$.

Coren, S., Girgys, J., Erlichman, H., \& Hakstian, R. (1976). An empirical taxonomy of visual illusions. Perception \& Psychophysics, 20(2), 129-137.

Coren, S., \& Porac, C. (1987). Individual differences in visual-geometric illusions: Predictions from measures of spatial cognitive abilities. Perception \& Psychophysics, 41(3), 211-219.

D'Oliveria, T. (2004). Dynamic spatial ability: An exploratory analysis and a confirmatory study. The International Journal of Aviation Psychology, 14(1), 19-38.

De Smedt, B., Janssen, R., Bouwens, K., Verschaffel, L., Boets, B., \& Ghesquière, P. (2009). Working memory and individual differences in mathematics achievement: A longitudinal study from first grade to second grade. Journal of Experimental Child Psychology, 103(2), 186-201.

DeLucia, P., \& Liddell, G. (1998). Cognitive motion extrapolation and cognitive clocking in prediction motion tasks. Journal of Experimental Psychology: Human Perception and Performance, 24(3), 901-914.

Dimitriu, D. (2015). A, B, See... in 3D: a workbook to improve 3-D visualization skills. Vermont: Morgan \& Claypool Publishers.

Ebisch, S., Perrucci, M., Mercuri, P., Romanelli, R., Mantini, D., Romani, G. L., et al. (2012). Common and unique neuro-functional basis of induction, visualization, and spatial relationships as cognitive components of fluid intelligence. NeuroImage, 62(1), 331-342.

Ekstrom, R., French, J., Harman, H., \& Derman, D. (1976). Kit of factor-referenced cognitive tests. Princeton, New Jersey: Educational Testing Service.

Eliot, J., \& Smith, I. M. (1983). An international directory of spatial tests. Windsor, England: NFER-Nelson publishing company and Atlantic highlands, New Jersey: Humanities Press.

Fields, A., \& Shelton, A. (2006). Individual skill differences and large-scale environmental learning. Journal of Experimental Psychology: Learning, Memory, and Cognition, 32(3), 506-515. 
Finke, R., \& Freyd, J. (1994). Imagery. In R. Sternberg (Ed.), Encyclopedia of human intelligence (pp. 561-563). New York: Macmillan.

Flanagan, J., Dailey, J., Shaycoft, M., Gorham, W., Orr, D., \& Goldberg, I. (1962). Design for a study of American youth. Boston: Houghton Mifflin Company.

Floyd, R. (2005). Information-processing approaches to interpretation of contemporary intellectual assessment instruments. In D. Flanagan \& P. Harrison (Eds.), Contemporary intellectual assessment: Theories, tests, and issues (pp. 203-233). New York and London: The Guilford Press.

Galton, F. (1879). Generic images. The Nineteenth Century, 6(1), 157-169.

Galton, F. (1880). Mental imagery. Fortnightly Review, 28(1), 312-324.

Gaughran, W. (2002). Cognitive modelling for engineers. In 2002 American Society for Engineering Education annual conference and exposition. Montréal, Canada: American Society for Engineering Education.

Gersmehl, P. (2005). Teaching geography. New York: Guilford Press.

Gibson, J. (1947). Motion picture testing and research. AD 651783. Washington DC: US Government Printing Office.

Gohm, C., Humphreys, L., \& Yao, G. (1998). Underachievement among spatially gifted students. American Educational Research Journal, 35(3), 515-531.

Golledge, R. (2002). The nature of geographic knowledge. Annals of the Association of American Geographers, 92(1), 1-14.

Groh, J. (2014). Making space: How the brain knows where things are. Cambridge, Massachusetts and London, England: Harvard University Press.

Guay, R. (1977). Purdue spatial visualization test: Rotations. West Lafayette, Indiana: Purdue Research Foundation.

Guilford, J. P. (1966). Intelligence: 1965 model. American Psychologist, 22(1), 20-26.

Guilford, J. P. (1967). The nature of human intelligence. New York, St. Louis, San Francisco, Toronto, London and Sydney: McGraw-Hill Book Company.

Haag, J., \& Borst, A. (2004). Neural mechanism underlying complex receptive field properties of motionsensitive interneurons. Nature Neuroscience, 7(6), 628-634.

Hambrick, D., Libarkin, J., Petcovic, H., Baker, K., Elkins, J., Callahan, C., et al. (2012). A test of the circumvention-of-limits hypothesis in scientific problem solving: The case of geological bedrock mapping. Journal of Experimental Psychology: General, 141(3), 397-403.

Hambrick, D., \& Meinz, E. (2011). Limits on the predictive power of domain-specific experience and knowledge in skilled performance. Current Directions in Psychological Science, 20(5), 275-279.

Harle, M., \& Towns, M. (2010). A review of spatial ability literature, its connection to chemistry, and implications for instruction. Journal of Chemical Education, 88(3), 351-360.

Harris, J., Hirsh-Pasek, K., \& Newcombe, N. (2013). Understanding spatial transformations: Similarities and differences between mental rotation and mental folding. Cognitive Processing, 14(2), 105-115.

Hawes, Z., Moss, J., Caswell, B., \& Poliszczuk, D. (2015). Effects of mental rotation training on children's spatial and mathematics performance: A randomized controlled study. Trends in Neuroscience and Education, 4(3), 60-68.

Hegarty, M., Montello, D., Richardson, A., Ishikawa, T., \& Lovelace, K. (2006). Spatial abilities at different scales: Individual differences in aptitude-test performance and spatial-layout learning. Intelligence, 34(2), 151-176.

Hegarty, M., \& Waller, D. (2004). A dissociation between mental rotation and perspective-taking spatial ability. Intelligence, 32(2), 175-191.

Heil, M., \& Jansen-Osmann, P. (2008). Sex differences in mental rotation with polygons of different complexity: Do men utilize holistic processes whereas women prefer piecemeal ones? The Quarterly Journal of Experimental Psychology, 61(5), 683-689.

Hodgkiss, A., Gilligan, K., Tolmie, A., Thomas, M., \& Farran, E. (2018). Spatial cognition and science achievement: The contribution of intrinsic and extrinsic spatial skills from 7 to 11 years. British Journal of Educational Psychology. https://doi.org/10.1111/bjep.12211.

Holzinger, K. J., \& Harman, H. (1938). Comparison of two factorial analyses. Psychometrika, 3(1), 45-60.

Holzinger, K. J., \& Swineford, F. (1939). A study in factor analysis: The stability of a bi-factor solution. Supplementary Educational Monographs, 48(1).

Howe, C., \& Purves, D. (2005). Perceiving geometry: Geometrical illusions explained by natural scene statistics. New York: Springer.

Hubel, D., \& Wiesel, T. (1959). Receptive fields of single neurones in the cat's striate cortex. Journal of Physiology, 148(3), 574-591.

Humphreys, L., Lubinski, D., \& Yao, G. (1993). Utility of predicting group membership and the role of spatial visualization in becoming an engineer, physical scientist, or artist. Journal of Applied Psychology, 78(2), 250-261.

Humphreys, L., \& Yao, G. (2002). Prediction of graduate major from cognitive and self-report test scores obtained during the high school years. Psychological Reports, 90(1), 3-30. 
Hunt, E., Pellegrino, J., Frick, R., Farr, S., \& Alderton, D. (1988). The ability to reason about movement in the visual field. Intelligence, 12(1), 77-100.

Höffler, T. (2010). Spatial ability: Its influence on learning with visualizations-A meta-analytic review. Educational Psychology Review, 22(3), 245-269.

Ishikawa, T., \& Montello, D. (2006). Spatial knowledge acquisition from direct experience in the environment: Individual differences in the development of metric knowledge and the integration of separately learned places. Cognitive Psychology, 52(2), 93-129.

Jensen, A. (1998). The g factor: The science of mental ability. Connecticut: Greenwood Publishing Group.

Johansson, B. (1965). Criteria for school readiness: Factor structure, predictive value and environmental influences. Stockholm, Sweden: Almqvist \& Wiksell.

Jones, S., \& Burnett, G. (2008). Spatial ability and learning to program. Human Technology: an Interdisciplinary Journal on Humans in ICT Environments, 4(1), 47-61.

July, R. (2001). Thinking in three dimensions: Exploring students' geometric thinking and spatial ability with geometer's sketchpad. Florida International University.

Kirschner, P., \& van Merriënboer, J. (2013). Do learners really know best? Urban legends in education. Educational Psychologist, 48(3), 169-183.

Klatzky, R. (1998). Allocentric and egocentric spatial representations: Definitions, distinctions and interconnections. In C. Freksa, C. Habel, \& K. Wender (Eds.), Spatial cognition: An interdisciplinary approach to representing and processing spatial knowledge (pp. 1-17). Verlag, Berlin, Heidelberg: Springer.

Kosslyn, S. (1981). The medium and the message in mental imagery: A theory. Psychological Review, 88(1), 46-66.

Kozhevnikov, M., \& Hegarty, M. (2001). A dissociation between object manipulation spatial ability and spatial orientation ability. Memory \& Cognition, 29(5), 745-756.

Kozhevnikov, M., Motes, M., \& Hegarty, M. (2007). Spatial visualization in physics problem solving. Cognitive Science, 31(4), 549-579.

Kozhevnikov, M., Motes, M., Rasch, B., \& Blajenkova, O. (2006). Perspective-taking vs. mental rotation transformations and how they predict spatial navigation performance. Applied Cognitive Psychology, 20(3), 397-417.

Kvist, A., \& Gustafsson, J.-E. (2008). The relation between fluid intelligence and the general factor as a function of cultural background: A test of Cattell's investment theory. Intelligence, 36(5), 422-436.

Kyllonen, P., \& Chaiken, S. (2003). Dynamic spatial ability and psychomotor performance. International Journal of Testing, 3(3), 233-249.

Larson, G. (1996). Mental rotation of static and dynamic figures. Perception \& Psychophysics, 58(1), 153-159.

Lee, J., \& Bednarz, R. (2012). Components of spatial thinking: Evidence from a spatial thinking ability test. Journal of Geography, 111(1), 15-26.

Letteri, C. (1980). Cognitive profile: Basic determinant of academic achievement. The Journal of Educational Research, 73(4), 195-199.

Lin, C.-H., \& Chen, C.-M. (2016). Developing spatial visualization and mental rotation with a digital puzzle game at primary school level. Computers in Human Behavior, 57(1), 23-30.

Lin, H. (2016). Influence of design training and spatial solution strategies on spatial ability performance. International Journal of Technology and Design Education, 2016(1), 123-131.

Linn, M., \& Petersen, A. (1985). Emergence and characterization of sex differences in spatial ability: A metaanalysis. Child Development, 56(6), 1479-1498.

Lohman, D. (1979). Spatial ability: A review and reanalysis of the correlational literature. Office of Naval Research.

Lohman, D. (1996). Spatial ability and g. In I. Dennin \& P. Tapsfield (Eds.), Human abilities: Their nature and measurement (pp. 97-116). New Jersey: Lawrence Erlbaum Associates.

Lorenz, C., \& Neisser, U. (1986). Ecological and psychometric dimensions of spatial ability. Atlanta, Georgia.

Lubinski, D. (2010). Spatial ability and STEM: A sleeping giant for talent identification and development. Personality and Individual Differences, 49(4), 344-351.

Marunic, G., \& Glazar, V. (2013). Spatial ability through engineering graphics education. International Journal of Technology and Design Education, 23(3), 703-715.

McGee, M. (1979). Human spatial abilities: Psychometric studies and environmental, genetic, hormonal and neurological influences. Psychological Bulletin, 86(5), 889-918.

McGrew, K. (2009). CHC theory and the human cognitive abilities project: Standing on the shoulders of the giants of psychometric intelligence research. Intelligence, 37(1), 1-10.

McGrew, K., \& Evans, J. (2004). Internal and external factorial extensions to the Cattell-Horn-Carroll (CHC) theory of cognitive abilities: A review of factor analytic research since Carroll's seminal 1993 treatise. Carroll human cognitive abilities (HCA) project research report \#2.

McKusick, V. (1969). On lumpers and splitters, or the nosology of genetic disease. Perspectives in Biology and Medicine, 12(2), 298-312. 
Meehl, P. (2006). The power of quantitative thinking. In N. Waller, L. Yonce, W. Grove, D. Faust, \& M. Lenzenweger (Eds.), A Paul Meehl reader: Essays on the practice of scientific psychology (pp. 433-444). Mahwah, New Jersey: Erlbaum.

Moreau, D. (2013). Differentiating two- from three-dimensional mental rotation training effects. The Quarterly Journal of Experimental Psychology, 66(7), 1399-1413.

Newcombe, N., \& Shipley, T. (2014). Thinking about spatial thinking: New typology, new assessments. In J. Gero (Ed.), Studying visual and spatial reasoning for design creativity (pp. 179-192). Netherlands: Springer.

Olkun, S. (2003). Making connections: Improving spatial abilities with engineering drawing activities. International Journal of Mathematics Teaching and Learning, 3(1), 1-10.

Olson, D. (2004). The triumph of hope over experience in the search for "what works": A response to Slavin. Educational Researcher, 33(1), 24-26.

Pellegrino, J., \& Hunt, E. (1989). Computer-controlled assessment of static and dynamic spatial reasoning. In R. Dillon \& J. Pellegrino (Eds.), Testing: Theoretical and applied perspectives (pp. 174-198). New York: Praeger Publishers.

Pellegrino, J., Hunt, E., Abate, R., \& Farr, S. (1987). A computer-based test battery for the assessment of static and dynamic spatial reasoning abilities. Behaviour Research Methods, Instruments \& Computers, 19(2), 231-236.

Pittalis, M., \& Christou, C. (2010). Types of reasoning in 3D geometry thinking and their relation with spatial ability. Educational Studies in Mathematics, 75(2), 191-212.

Poltrock, S., \& Agnoli, F. (1986). Are spatial visualization ability and visual imagery equivalent. In R. Sternberg (Ed.), Advances in the psychology of human intelligence (pp. 255-296). New Jersey: Lawrence Erlbaum Associates.

Primi, R., Ferrão, M. E., \& Almeida, L. (2010). Fluid intelligence as a predictor of learning: A longitudinal multilevel approach applied to math. Learning and Individual Differences, 20(5), 446-451.

Raghubar, K., Barnes, M., \& Hecht, S. (2010). Working memory and mathematics: A review of developmental, individual difference, and cognitive approaches. Learning and Individual Differences, 20(2), 110-122.

Ramey, K., \& Uttal, D. (2017). Making sense of space: Distributed spatial sensemaking in a middle school summer engineering camp. Journal of the Learning Sciences, 26(2), 277-319.

Rochford, K. (1985). Spatial learning disabilities and underachievement among university anatomy students. Medical Education, 19(1), 13-26.

Roff, M. (1952). A factorial study of tests in the perceptual area. Psychometric Monographs No.8, 8(1), 1-41.

Russell-Gebbett, J. (1985). Skills and strategies - pupils' approaches to three-dimensional problems in biology. Journal of Biological Education, 19(4), 293-298.

Sanchez, C., \& Wiley, J. (2014). The role of dynamic spatial ability in geoscience text comprehension. Learning and Instruction, 31(1), 33-45.

Saunders, D. (1959). On the dimensionality of the WAIS battery for two groups of normal males. Psychological Reports, 5(h), 529-541.

Saunders, D. (1960). A factor analysis of the picture completion items of the WAIS. Journal of Clinical Psychology, 16(2), 146-149.

Schneider, J., \& McGrew, K. (2012). The Cattell-Horn-Carroll model of intelligence. In D. Flanagan \& P. Harrison (Eds.), Contemporary intellectual assessment: Theories, tests, and issues (3rd ed., pp. 99-144). New York: Guilford Press.

Seery, N. (2017). Modelling as a form of critique. In P. J. Williams \& K. Stables (Eds.), Critique in design and technology education (pp. 255-273). Singapore: Springer.

Shea, D., Lubinski, D., \& Benbow, C. (2001). Importance of assessing spatial ability in intellectually talented young adolescents: A 20-year longitudinal study. Journal of Educational Psychology, 93(3), 604-614.

Small, M., \& Morton, M. (1983). Research in college science teaching: Spatial visualization training improves performance in organic chemistry. Journal of College Science Teaching, 13(1), 41-43.

Smith, I. M. (1964). Spatial ability: Its educational and social significance. Michigan: R.R. Knapp.

Sorby, S. (1999). Developing 3-D spatial visualization skills. Engineering Design Graphics Journal, 63(2), 21-32.

Sorby, S. (2009). Educational research in developing 3-D spatial skills for engineering students. International Journal of Science Education, 31(3), 459-480.

Sorby, S., \& Baartmans, B. (1996). A course for the development of 3-D spatial visualization skills. Engineering Design Graphics Journal, 60(1), 13-20.

Sorby, S., \& Baartmans, B. (2000). The development and assessment of a course for enhancing the 3-D spatial visualization skills of first year engineering students. Journal of Engineering Education, 89(3), 301-307.

Sorby, S., Casey, B., Veurink, N., \& Dulaney, A. (2013). The role of spatial training in improving spatial and calculus performance in engineering students. Learning and Individual Differences, 26(1), 20-29.

Spearman, C. (1904). "General intelligence," objectively determined and measured. The American Journal of Psychology, 15(2), 201-292. 
Spearman, C. (1927). The abilities of man, their nature and measurement. London, Bombay, Calcutta, madras. Melbourne: Macmillan.

Sternberg, R. (2000). The concept of intelligence. In R. Sternberg (Ed.), Handbook of intelligence (pp. 3-15). Cambridge: Cambridge University Press.

Stieff, M., \& Uttal, D. (2015). How much can spatial training improve STEM achievement? Educational Psychology Review, 27(4), 607-615.

Sutton, K., \& Allen, R. (2011). Assessing and improving spatial ability for design-based disciplines utilising online systems. Australia: New South Wales.

Suzuki, K., Wakita, S., \& Nagano, S. (1990). Improvement of spatial ability through descriptive geometry education. Journal of Graphic Science of Japan, 24(1), 21-28.

Terlecki, M., Newcombe, N., \& Little, M. (2008). Durable and generalized effects of spatial experience on mental rotation: Gender differences in growth patterns. Applied Cognitive Psychology, 22(7), 996-1013.

Thompson, W., Slotnick, S., Burrage, M., \& Kosslyn, S. (2009). Two forms of spatial imagery: Neuroimaging evidence. Psychological Science, 20(10), 1245-1253.

Thurstone, L. L. (1938). Primary mental abilities. Chicago: Chicago University Press.

Tversky, B. (2005). Visuospatial reasoning. In K. Holyoak \& R. Morrison (Eds.), The Cambridge handbook of thinking and reasoning (pp. 209-240). New York: Cambridge University Press.

Uttal, D., \& Cohen, C. (2012). Spatial thinking and STEM education: When, why, and how? Psychology of Learning and Motivation, 57(1), 147-181.

Uttal, D., Meadow, N., Tipton, E., Hand, L., Alden, A., Warren, C., \& Newcombe, N. (2013). The malleability of spatial skills: A meta-analysis of training studies. Psychological Bulletin, 139(2), 352-402.

Van de Weijer -Bergsma, E., Kroesbergen, E., \& Van Luit, J. (2015). Verbal and visual-spatial working memory and mathematical ability in different domains throughout primary school. Memory \& Cognition, 43(3), 367378.

Vernon, P. (1950). The structure of human abilities. New York: Wiley.

Wai, J., Lubinski, D., \& Benbow, C. (2009). Spatial ability for STEM domains: Aligning over 50 years of cumulative psychological knowledge solidifies its importance. Journal of Educational Psychology, 101(4), $817-835$.

Wang, L., Cohen, A., \& Carr, M. (2014). Spatial ability at two scales of representation: A meta-analysis. Learning and Individual Differences, 36(1), 140-144.

Wasserman, J., \& Tulsky, D. (2005). A history of intelligence assessment. In D. Flanagan \& P. Harrison (Eds.), Contemporary intellectual assessment: Theories, tests, and issues (pp. 3-22). New York and London: The Guilford Press.

Webb, R., Lubinski, D., \& Benbow, C. (2007). Spatial ability: A neglected dimension in talent searches for intellectually precocious youth. Journal of Educational Psychology, 99(2), 397-420.

Weisberg, S., Schinazi, V., Newcombe, N., Shipley, T., \& Epstein, R. (2014). Variations in cognitive maps: Understanding individual differences in navigation. Journal of Experimental Psychology: Learning, Memory, and Cognition, 40(3), 669-682.

Wise, L., McLaughlin, D., \& Steel, L. (1979). The project TALENT data bank handbook. California: American Institutes for Research.

Wright, R., Thompson, W., Ganis, G., Newcombe, N., \& Kosslyn, S. (2008). Training generalized spatial skills. Psychonomic Bulletin \& Review, 15(4), 763-771.

Wu, H.-K., \& Shah, P. (2004). Exploring visuospatial thinking in chemistry learning. Science Education, 88(3), 465-492.

Yuan, K., Steedle, J., Shavelson, R., Alonzo, A., \& Oppezzo, M. (2006). Working memory, fluid intelligence, and science learning. Educational Research Review, 1(2), 83-98. 